\title{
La cicatriz (in)visible \\ La representación del cuerpo en blogs de mujeres con cáncer de mama
}

\author{
Gerard COLL-PLANAS ${ }^{1}$ \\ Universitat de Vic-Universitat Central de Catalunya \\ gerard.coll@uvic.cat \\ Mariona Visa BARBOSA ${ }^{2}$ \\ Universitat de Lleida \\ marionavisa@filcat.udl.cat
}

Recibido: 20-05-2014

Aceptado: 16-04-2015

\section{Resumen}

En este artículo analizamos la representación del cuerpo en blogs de mujeres con cáncer de mama. Fijándonos tanto en los textos como en las imágenes, estudiamos la representación del cuerpo a partir de las problemáticas corporales planteadas por Frank (1995): control, relación con el cuerpo, relación con los demás y deseo. En los blogs analizados aparece un cuerpo deseante y que se entiende de una forma diádica, formando parte de una red de afectos y cuidados. El diagnóstico de cáncer puede generar tanto disociación del cuerpo (que es vivido como una amenaza), como asociación, una mayor conexión. En relación al control, se observa una clara voluntad de predictibilidad aunque también aparecen indicios de asunción de la contingencia.

Palabras clave: cáncer, blogs, cuerpo, enfermedad, género.

${ }^{1}$ Grup de recerca Estudis de gènere: traducció, literatura, història i comunicación (GETLIHC), Universitat de Vic-Universitat Central de Catalunya. ORCID: 0000-0002-2294-2707.

${ }^{2}$ Grup d'Estudis de la Cultura i les Identitats a l'Europa Contemporània (GECIEC), Universitat de Lleida. ORCID: 0000-0002-9261-264X. 


\title{
The (In)Visible Scar \\ Representation of the Body in Blogs by Women with Breast Cancer
}

\begin{abstract}
In this paper we analyze the representation of the body in blogs by women with breast cancer. Taking into account both texts and images, we study the representation of the body on the basis of the body problems proposed by Frank (1995): control, body-relatedness, other-relatedness and desire. In the blogs studied we find a desiring and dyadic body, which is understood as part of a network of affection and care. The diagnosis of cancer can generate both dissociation, when the body is experienced as a threat, and association, a wish to be connected to it. In relation to control, a clear will of predictability is observed but traces of assumption of contingency also appear.

Keywords: Cancer; Internet; Body; Illness; Gender.

\section{Referencia normalizada}

Coll-Planas, Gerard y Mariona Visa Barbosa (2015): “La cicatriz (in)visible. La representación del cuerpo en blogs de mujeres con cáncer de mama”, Política y Sociedad, 52 (2), pp. 487 507.
\end{abstract}

Sumario: 1. Introducción. 2. Las problemáticas corporales. 3. Método y trabajo de campo. 4. Análisis. 5. Conclusiones. 6. Bibliografía.

\section{Agradecimientos}

Queremos agradecer a las autoras de los blogs el hecho de compartir sus experiencias y reflexiones alrededor del cáncer de mama con honestidad y valentía. 


\section{Introducción}

A través de las narrativas las personas enfermas pueden dar cuenta de sus experiencias, dar sentido a su sufrimiento y establecer una mirada propia sobre el proceso vivido (Mathieson y Hendaikns, 1995). El interés por las narrativas de la enfermedad por parte de las ciencias sociales debe contextualizarse en el marco del giro lingüístico y se hace patente a partir de la década de 1980 (Hydén, 1997). Desde entonces, las investigaciones sobre las narrativas han sido muy prolíficas en el campo de la sociología de la salud (Pierret, 2003; Thomas, 2010). Desde la medicina se han visto con escepticismo (Hydén, 1997; Fisher y Goodley, 2007; Shapiro, 2011), aunque actualmente se está apreciando un creciente interés por la información que producen y el efecto beneficioso del hecho de narrar para la salud de la persona enferma (Gualtieri y Akhtar, 2013) en el marco del movimiento hacia una medicina más centrada en el paciente (Shapiro, 2011).

Internet se ha convertido en un lugar privilegiado en el que compartir experiencias y conocimiento relativo a la salud, ya sea a través de foros, listas de correos electrónicos, grupos de autoayuda online, blogs personales, webs institucionales o redes sociales (Seale, 2005; Gooden y Winefield, 2007; Wentzer y Bygholm, 2013). Las narrativas presentes en los blogs han sido poco utilizadas como fuente de información cualitativa sobre la experiencia de la enfermedad (Gualtieri y Akhtar, 2013), aunque encontramos algunas excepciones como McCosker (2008), Ressler et al. (2012) y Gualtieri y Akhtar (2013).

Alrededor de 24.000 blogs tratan temas relacionados con la salud, la mayoría de los cuales son sobre cáncer, y muy especialmente cáncer de mama (Gualtieri y Akhtar, 2013). Los blogs ofrecen muchas posibilidades comunicativas debido a que pueden incorporar imágenes y vídeos, y porque permiten un conocimiento muy profundo del proceso vivido gracias a que en ellos las personas pueden dar cuenta del día a día de la enfermedad (McCosker, 2008).

El objetivo del artículo es analizar la representación (textual y gráfica) del cuerpo en blogs escritos por mujeres con cáncer de pecho. El análisis se articulará a partir de las problemáticas corporales apuntadas por Frank (1995). Así, este artículo se enmarca en la reflexión acerca de las posibilidad que ofrece la esfera pública digital de empoderamiento de las pacientes, entendiendo que éste se produce cuando "están en posesión del conocimiento, las habilidades y la conciencia de sí mismos necesarios para identificar y alcanzar sus objetivos"3 (Wentzer y Bygholm, 2013: 387). De esta forma, nos preguntamos hasta qué punto en la esfera pública digital encontramos narrativas que reproducen la lógica biomédica moderna u ofrece nuevas posibilidades de empoderamiento, de generación de conocimiento y de representación del cuerpo (Pitts, 2004; Seale, 2005).

En los siguientes apartados planteamos los aspectos teóricos que guían el presente artículo, presentamos el trabajo de campo llevado a cabo y el método de análisis. A

\footnotetext{
${ }^{3}$ Las traducciones al castellano de las citas originales en inglés son de los propios autores del artículo.
} 
continuación analizamos el material de los blogs a partir de las problemáticas corporales. Finalmente, en las conclusiones, sintetizamos las aportaciones del análisis y reflexionamos sobre si la esfera pública digital ofrece posibilidades de generar un nuevo discurso sobre la enfermedad.

\section{Las problemáticas corporales}

La productividad y vigencia de las aportaciones de Frank (1995) a la sociología de la salud las evidencian los estudios recientes que continúan utilizando sus categorías analíticas para el estudio de las narrativas sobre, por ejemplo, la diabetes (Karas y Karner, 2005), el cáncer de mama (Thomas-MacLean, 2004; Sumalla et al., 2013), la menopausia (Nosek et al., 2012) o la discapacidad adquirida (Smith y Sparkes, 2008). A diferencia de la mayoría de investigaciones citadas, que se centran en la tipología de narrativas que propone el autor, el presente artículo aplica su tipología de problemas corporales. Otros aspectos que distinguen el presente trabajo son el corpus de análisis (blogs) y el hecho de analizar conjuntamente el discurso escrito y gráfico.

El análisis de los blogs se estructurará, pues, en base a las cuatro problemáticas en relación a la corporalidad que emergen con especial claridad ante un proceso de enfermedad. Cada problemática es presentada como un continuum que se mueve entre dos extremos.

La primera problemática, el deseo, Frank (1995) lo entiende desde un marco psicoanalítico, no como ligado a la sexualidad en sentido estricto, sino en un sentido amplio (Bekerman, 1996). Esta aproximación es coherente con la forma en que parte de los estudios feministas han definido la sexualidad "no genitalizada, que no tiene como única meta el orgasmo, dúctil, energía de base para la unión erótica, la amistad, el compromiso político y científico" (Izquierdo, 1998: 121). Desde esta perspectiva el autor distingue si el cuerpo aparece productivo, deseante o, por el contrario, es presentado con falta de deseo, indiferente, sin voluntad.

La segunda problemática, la relación con los demás, distingue si el cuerpo se experimenta como monádico (como una unidad aislada) o diádico (en relación con otros cuerpos). La tendencia dominante, fomentada por la medicina, es entender el cuerpo de forma monádica (Martin, 2001; Le Breton, 2002; Karas y Karner, 2005), pero Frank (1995) apunta que la experiencia de la enfermedad puede ser la base para sentir empatía con los demás.

La tercera problemática, la relación con el cuerpo, distingue si la persona se siente asociada a su corporalidad (es cuerpo) o disociada, lo siente como algo ajeno (la persona tiene un cuerpo), siguiendo así el dualismo cartesiano de la división cuerpo/mente, estableciendo esta última como lo esencial del sujeto (Turner, 1992). Frank (1995) plantea que la vivencia del cuerpo saludable promueve que lo sintamos como algo propio, mientras que la enfermedad y la mortalidad fomentan que lo vivamos como ajeno. En los mismos términos se expresa Turner (1992: 40): "En casos de enfermedad, esta 
experiencia de tener un cuerpo es a menudo acusada, ya que el cuerpo aparece como un fenómeno objetivo y externo".

La cuarta problemática es el control, y establece un eje en un extremo del cual aparece el cuerpo predictible y en el otro, el contingente. La enfermedad es un proceso que evidencia la contingencia del cuerpo, el cual escapa al control del sujeto. Esta falta de predictibilidad asociada a la enfermedad, choca con el ideal moderno de que el conjunto de la existencia humana (incluida la corporalidad) esté controlada por el ser humano (Frank, 1995; Elias, 1989; Bauman, 1992). Dentro de esta lógica, el discurso médico concibe la muerte como algo evitable: cada causa particular de muerte puede ser resistida, pospuesta o evitada. Esta forma de lidiar con la contingencia, que Bauman (1992) llama 'lenguaje de la supervivencia', ofrece una vía de escape al miedo a la muerte: la preocupación ajetreada por la salud y la higiene. Así, el inmenso e incontrolable miedo a la muerte se fragmenta en una infinidad de tareas concretas que están a nuestro alcance. En este marco, la causa de la enfermedad se atribuye al individuo por no haber sido capaz de controlar su cuerpo a través de aspectos como la alimentación, la actividad física o la gestión emocional (Bell, 2010; Sumalla et al., 2013).

Frank (1995) diferencia la forma moderna y posmoderna de experimentar la enfermedad, que implican diferentes tipos ideales de cuerpo. En la forma moderna la experiencia es "colonizada" por el conocimiento médico, lo que para el autor implica una "rendición", pues "la persona enferma no solo acepta seguir las indicaciones médicas, también acepta (...) contar su historia en términos médicos" (Frank, 1995: 6). En este marco, impera la lógica del 'lenguaje de la supervivencia' (Bauman, 1992) y se promueve un cuerpo predictible, disociado, monádico y cuyo deseo está dirigido a cumplir los preceptos médicos para volver al estadio previo a la enfermedad.

En contraposición, la experiencia posmoderna de la enfermedad empieza cuando las personas reclaman la capacidad de dar cuenta de su experiencia de una forma autónoma al poder médico (Frank, 1995). Esto implica una creciente desconfianza respecto la medicina y una voluntad de representarse en vez de ser representados. Así, promueve un cuerpo que acepta la contingencia, asociado, diádico y productivo a nivel de deseo.

\section{Método y trabajo de campo}

El corpus de análisis han sido blogs escritos por mujeres con cáncer de mama, que giran alrededor de este tema y están escritos en castellano. Para establecer la muestra, hemos hecho una exploración para localizar blogs que cumplieran estas características. De los 13 blogs encontrados se seleccionaron los más prolíficos en función del número de entradas publicadas (en marzo de 2013). Se dio por cerrada la selección, siguiendo el criterio de saturación de la muestra, cuando ya no aparecían nuevos discursos. Así, se seleccionaron siete blogs que, en conjunto, suman 597 entradas. 
Tabla 1: Muestra de Blogs analizados ${ }^{4}$

\begin{tabular}{|c|c|c|c|c|c|c|}
\hline $\mathrm{N}$ & Título del blog & Enlace & $\begin{array}{l}\text { Edad } \\
\text { autora }\end{array}$ & $\begin{array}{l}\text { Período } \\
\text { actividad }^{2}\end{array}$ & $\begin{array}{l}\text { Núm. } \\
\text { entradas }\end{array}$ & $\begin{array}{l}\text { Núm. } \\
\text { entradas } \\
\text { con } \\
\text { imagen }\end{array}$ \\
\hline 1 & $\begin{array}{l}\text { Memorias de un } \\
\text { cáncer de mama }\end{array}$ & $\begin{array}{l}\text { http://memoriasdeuncancer. } \\
\text { blogspot.com.es/ }\end{array}$ & 31 & 2010-actual & 133 & 51 \\
\hline 2 & $\begin{array}{l}\text { Una sonrisa y } \\
\text { mil pañuelos }\end{array}$ & $\begin{array}{l}\text { http:// } \\
\text { elblogdeainaratrigueros. } \\
\text { blogspot.com.es/ }\end{array}$ & 33 & 2011-actual & 108 & 76 \\
\hline 3 & $\begin{array}{l}\text { Cáncer de } \\
\text { mama, mi } \\
\text { maestr@ }\end{array}$ & $\begin{array}{l}\text { http:// } \\
\text { supervivirauncancerdemama. } \\
\text { blogspot.com.es/ }\end{array}$ & 28 & 2008-actual & 84 & 17 \\
\hline 4 & $\begin{array}{l}\text { Blog de María } \\
\text { Antonia } \\
\text { Valdivielso }\end{array}$ & $\begin{array}{l}\text { http:// } \\
\text { mariaantoniavaldivielso. } \\
\text { blogspot.com.es/ }\end{array}$ & 40 & 2008-2009 & 81 & 27 \\
\hline 5 & $\begin{array}{l}\text { ¡Sí sin mis } \\
\text { pechos! }\end{array}$ & $\begin{array}{l}\text { http://sisinmispechos. } \\
\text { blogspot.com.es/ }\end{array}$ & 45 & $2008-2010$ & 79 & 70 \\
\hline 6 & Sobrevivir & $\begin{array}{l}\text { http://eva-aguilera.blogspot. } \\
\text { com.es/ }\end{array}$ & 33 & 2011-actual & 75 & 35 \\
\hline 7 & $\begin{array}{l}\text { Marimachos } \\
\text { Cancerosas }\end{array}$ & $\begin{array}{l}\text { http://marimachoscancerosas. } \\
\text { blogspot.com.es/ }\end{array}$ & $30-45$ & 2013-actual & 37 & 37 \\
\hline
\end{tabular}

Fuente: elaboración propia.

Todos los blogs son individuales, excepto el 5 y el 7. En el caso del 5, en 18 entradas el marido de la autora escribe breves intervenciones. El 7 se concibe como un proyecto colectivo y abierto a la participación: cuatro mujeres han participado en el blog hasta la fecha analizada.

Los blogs del 1 al 6 tienen como finalidad compartir sus experiencias, reflexiones y consejos en relación al cáncer de mama. El 7, en cambio, tiene un tono menos testimo-

${ }^{4}$ Edad autora se refiere a la misma al iniciar el blog.

Periodo de actividad: los blogs que han dejado de ser actualizados, sus autoras los mantienen visibles en el ciberespacio. 
nial y más político, pretendiendo cuestionar la forma dominante de entender el cáncer de mama.

Sobre la posición socioestructural de las autoras, la información que se puede extraer de los blogs es desigual y muy limitada. En todos los casos, las mujeres viven en el Estado español, están entre la treintena y la cuarentena y tienen estudios universitarios y trabajos cualificados. Este sesgo de clase confirma la crítica de Seale (2005) a los autores que enfatizan el potencial democrático de internet: a pesar de este potencial, encontramos sesgos (en este caso en relación a la edad y a la clase social) que evidencian un acceso desigual a la producción de conocimiento a través de los recursos que ofrece la esfera pública digital.

De los blogs seleccionados se ha analizado tanto el texto como las imágenes. En relación al texto, todas las entradas fueron volcadas a una matriz Excel y codificadas a partir de las categorías analíticas surgidas de las cuatro problemáticas corporales y los extremos de sus respectivos ejes (ver apartado 2). Una vez codificado el material, fue analizado mediante análisis de discurso, partiendo de una concepción del lenguaje como productor de la realidad (Cabruja et al., 2000). Desde esta perspectiva, pretendemos entender cómo se construye la interpretación de la realidad, desvelando cómo las construcciones discursivas de las mujeres que tienen cáncer de mama reproducen determinadas concepciones del cuerpo.

Referente a las imágenes, los post ilustrados se han clasificado según criterios descriptivos, compositivos y de representación social (Visa, 2013). El análisis descriptivo se centra en los elementos icónicos de la cabecera del blog, en el número de imágenes de cada post, en su procedencia y en la presencia de pies de fotografía o de texto. El análisis compositivo estudia las imágenes en función del tipo de plano, de su orientación, del ángulo de la toma y de la disposición de los elementos dentro del encuadre. Respecto a la representación social se han anotado aquellos elementos que informan del contexto de la imagen, del espacio mostrado, de las personas que aparecen y de la actividad principal representada.

Posteriormente se ha realizado un análisis más exhaustivo de las imágenes en que aparece el cuerpo, ya sea de las propias autoras o de otras personas. Esta submuestra está constituida por 181 imágenes, que han sido codificadas en base a las problemáticas corporales y a la representación de la enfermedad.

Aunque los blogs tienen un carácter público, en los casos en que las autora facilitan una forma de contacto (en 5 de los 7 blogs) nos hemos puesto en contacto con ellas para informarles de la investigación llevada a cabo, les hemos mandado una versión preliminar del artículo y les hemos ofrecido la posibilidad de anonimizar su blog. De las autoras que han contestado (4 de 5), todas han accedido a que analicemos su blog sin anonimizar.

Hay que señalar que las citas de los posts se presentan en su forma original, sin corregir aspectos ortográficos ni formales. 


\section{Análisis}

\subsection{Deseo}

La vertiente de la falta de deseo no está presente debido en gran parte al tipo de material analizado: la escritura y el mantenimiento de los blogs es ya una expresión de deseo de contar, de dar sentido a su proceso y de compartirlo (Frank, 1995; Karas y Karner, 2005). Así, una autora afirma que el blog se ha convertido en su "motor principal de lucha" (blog 2) y otra afirma que los mensajes que recibe "son como una descarga eléctrica, me dan fuerza, me hacen sentir viva y sobre todo que todo lo vivido no ha sido en vano" (blog 1).

La vertiente del deseo productivo también se muestra en la voluntad de emprender proyectos y actividades al margen de la convalecencia y el tratamiento: la creación de un blog sobre artesanía que abre la autora del blog 3; los numerosos viajes de las autoras de los blogs 4 y 6 (mostrados gráficamente en 19 ocasiones); el interés por reemprender la vida laboral que se refiere en los blogs 2 y 4 (mostrada en 7 posts); o los proyectos colectivos en los que participan (ver 4.2).

De hecho, el diagnóstico de cáncer promueve su deseo de llevar a cabo actividades ("se te pasan por la cabeza miles de cosas que aún no has hecho y que te gustaría hacer antes de palmarla", blog 6), hasta el punto que estos proyectos sirven de motivación para aguantar los momentos duros del proceso: "se me ocurren un millón de cosas por las que merece la pena luchar" (blog 2).

La enfermedad les muestra la brevedad de la vida, la necesidad de aprovechar el tiempo, de priorizar. Así, la autora del blog 1 expresa que "el diagnóstico del cáncer es capaz de devolvernos el sabor de la vida", y otras argumentan que la experiencia del cáncer les ha hecho experimentar la vida de una forma mucho más intensa. Este es el caso de la autora del blog 2, que afirma que el cáncer le ha hecho "VIVIR la VIDA de verdad, dando la intensidad que se merece cada segundo para poder exprimirlo a tope", y de la autora del blog 5, que después de saber que no tiene metástasis, afirma: "por primera vez en mi vida, me sentía viva de verdad... y de lo más profundo de mi ser nació una angustiosa necesidad de saborear cualquier segundo que la nueva existencia me regalara".

\subsection{Relación con los demás}

En los blogs principalmente encontramos una concepción diádica, pues escribir un blog muestra la voluntad de comunicarse, de compartir su experiencia con personas de su propio entorno o desconocidas. Aun así, las fotografías que muestran a las autoras sometiéndose al tratamiento o los efectos secundarios de éste suelen representarse de forma monádica y disociada (ver 4.3). 
Además del hecho de escribir un blog, la relación diádica a partir de la experiencia del cáncer se expresa en tres elementos que desarrollamos a continuación: la importancia de la mirada del otro, entenderse como un sujeto interdependiente y la enfermedad como un proceso que genera empatía y solidaridad.

En primer lugar, en relación a la mirada ajena, aparece insistentemente la preocupación por dejar de ser deseable debido a los efectos de la quimioterapia (sobre todo la alopecia), a las cicatrices o a la extirpación o malformación de los senos. La frecuencia en que aparece la preocupación por tener unos pechos deseables y sin rastro del proceso vivido contrastan con el hecho de que una sola vez, en el blog 5, se menciona la preocupación por la pérdida de placer erógeno de esta parte del cuerpo. En este sentido, Smith (2009) plantea que, en un orden androcéntrico, para las mujeres la importancia de la mirada masculina prevalece sobre su capacidad de sentir placer. Esta tendencia debemos ubicarla pues en un contexto sexista en que el interés por ser reconocidas y deseables es especialmente marcado en las mujeres (Coll-Planas et al., 2013).

La necesidad de sentirse deseables se traduce en la voluntad de arreglarse y de compartir consejos, reflexiones y experiencias sobre cómo mejorar la imagen (Sumalla et al., 2013). En los blogs 2 y 6 las autoras aparecen en ocasiones con la cara maquillada, resaltando especialmente los ojos, y difunden diferentes fotografías y vídeos sobre cómo colocarse el pañuelo. La autora del blog 4 aprovecha la baja durante la quimioterapia para apuntarse a un Ciclo de Asesoría de Imagen y cuenta en el blog sus trucos para esconder los efectos de la quimioterapia.

En este marco, la alopecia es señalada como un elemento central de preocupación:

La verdad que una vez te dicen que todo el tumor está localizado en el pecho sientes un alivio enorme. (...) a partir de ese momento mi "gran preocupación" pasó a ser EL PELO. El médico me explicaba que quizás me tendrían que cortar el pecho y yo solo lloraba al pensar que me iba a quedar calva. No sabía que iba a hacer. Me atrevería a salir de casa? Seguiría gustando a mi novio? (blog 6)

En cualquier caso, como expresan las mismas blogueras, la voluntad de borrar o disimular el rastro corporal del cáncer y su tratamiento no se debe solo a la necesidad de gustar a los demás sino de escapar del estigma asociado al cáncer (Goffman, 1986).

En segundo lugar, en los blogs el cuerpo diádico aparece cuando se hace referencia al proceso de enfermedad y tratamiento no como una experiencia individual sino relacional. En este sentido, en los blogs están muy presentes las muestras de agradecimiento a todas las personas que las acompañan en el proceso:

Antes de que se me cayese el pelo quería estar preparada, y haciendo caso a otras amigas que están pasado por esto, (gracias Ana!!) me fui a mirar pelucas a mi medida. (...) Menos mal que mi amiga Oihana me acompañó a varios sitios y me empezó a hacerme fotos para que me las viese tranquilamente en casa. (...) Así que estando una tarde enfrente del ordenador me iba dejando los pelos encima de 
un papel blanco, cuando hice ya un mechón considerable llamé a la peluquería cogí a mi madre y a mi hermana y nos fuimos las tres juntitas a ver cómo me pelaban!!

(...) Como dice mi amigo Alvarito: "a las penas, puñalás!!” (blog 2)

En esta cita se muestra el reconocimiento del apoyo de los demás en la toma de decisiones, en la forma de vivir el proceso y en la voluntad de compartir la experiencia. La tendencia a explicar el proceso como algo relacional es un rasgo característico de las formas de narrar la enfermedad de las mujeres, en contraposición a los hombres, que suelen entenderse a sí mismos de forma más aislada, costándoles más reconocer la interdependencia (Seale, 2002; Pitts, 2004).

La lógica diádica de Frank (1995) que se detecta claramente en los textos se traduce solo parcialmente en las imágenes: la mayoría de las analizadas (83) muestran la autora del blog en solitario, en contraposición a las 47 en que aparece acompañada de amistades o familiares. Este desfase puede deberse al respeto por el derecho a la propia imagen de las personas más que a la voluntad de no mostrarlas, motivo explicitado por la autora del blog 2 .

Los blogs, además, acaban constituyendo una red alrededor de la autora, que ofrece consejos, recibe comentarios y, menos habitualmente, pide consejos. El blog como nodo de una red se evidencia a nivel gráfico en los comentarios que dejan algunos lectores después de un post y en el listado de blogs que se enlazan en la parte derecha de la página principal. Algunas autoras se refieren a esta red que se ha creado alrededor de su blog como "mi ciberfamilia de luchador@s" (blog 2) o como "hermandad" (blog 4). Esta idea está especialmente presente en el blog 7, cuya autoría es colectiva, y en el 2: "ya no me puedo ir a la cama sin saber que mis pelones están bien, o regular... pero que estamos ahí los unos para los otros".

En estos ejemplos se evidencia el planteamiento de Frank (1995) según el cual la experiencia de la enfermedad puede producir una sensación de empatía y unión respecto a las personas que sufren: "te hace empatizar con la gente que lo pasa mal e incluso llegas a anteponer su sufrimiento al tuyo" (blog 6). Así, en los blogs se pueden encontrar mensajes de apoyo a personas que están viviendo la enfermedad y recordatorios a personas que han fallecido.

En tercer lugar, en los blogs también se evidencia cómo la vivencia de la enfermedad lleva a algunas autoras de blogs a vincularse a proyectos colectivos. En los blogs se divulgan los eventos organizados por la Asociación Española contra el cáncer, como la carrera de la mujer contra el cáncer de mama en la que participan varias de las blogueras. Y algunas de ellas participan o mencionan proyectos fotográficos para dar visibilidad a la enfermedad, como The Scar Project ${ }^{5}$, Alma Fotografía Solidaria ${ }^{6}$ o Cos-

${ }^{5}<\mathrm{http}: / /$ www.thescarproject.org/> (consultada enero 2015).

${ }^{6}$ Actualmente no dispone de una web pública. Más información en Valerio (2013). 
turas a flor de piel ${ }^{7}$. El caso más claro de vinculación colectiva a raíz de la enfermedad es el de la autora del blog 2, que protesta sobre los recortes de sanidad, y es una de las iniciadoras de una campaña para la donación de médula y cordón umbilical, acción que llega a ocupar una parte importante de su blog.

Una forma diferente de acción colectiva la encontramos en el blog 7, que nace sentimiento de no pertenencia a los grupos de autoayuda para enfermas con cáncer de mama:

Acudí al lazo rosa (olé por todo el trabajo que hacen y el apoyo que me ofrecieron) pero era extraño, ajeno a mí. Yo marimacho, butch, trans....buscando empoderarme, buscando referentes. Encontré mujeres que se reunian para hablar de sus pelucas, de sus familias, de su feminidad, de las clases de pintura.......de un cotidiano "normal" que no era el mio!!!! (blog 7)

Este sentimiento de no pertenencia a los entornos establecidos no la llevó a un aislamiento sino a la creación y búsqueda de nuevos espacios en los que la vivencia del cáncer conectara con planteamientos críticos en relación al sistema heteronormativo. Desde este marco, critica el discurso dominante sobre el cáncer de mama por "vender el cáncer como un problema individual, sin asumir el impacto ambiental", por ser sexista y por el uso de esta enfermedad con motivos publicitarios. Este blog reivindica además la necesidad de crear un imaginario nuevo de la enfermedad desvinculado del heteronormativo, objetivo que se alcanza cuestionando las imágenes que habitualmente se generan desde los medios de comunicación o las instituciones. Así, aparecen cuerpos femeninos encadenados, silenciados o en la sombra. A éstas imágenes se yuxtaponen ilustraciones de caras que gritan o cuerpos que van ataviados como antiguos guerreros para reivindicar una toma de posición activa ante el cáncer.

\subsection{Relación con el cuerpo}

La experiencia de la enfermedad suele conducir a las autoras a conectar más con su cuerpo (especialmente en los blogs 1, 3, 6 y 7):

Antes de la enfermedad apenas escuchaba a mi cuerpo, (...) antes estaba sorda. Ahora mis sentidos están despiertos, escucho a mi cuerpo e intento darle lo que me pide para encontrar un equilibrio y sentirme más sana. (blog 1)

Desde una lectura menos individualista, una autora del blog 7 expresa que vivimos en una cultura en que se niega la corporalidad y en este sentido el cáncer ha sido una oportunidad para entender su importancia:

\footnotetext{
$7<$ http://costuras.org/> (consultada enero 2015).
} 
Un día grita! Tienes cáncer!!! maldito cuerpo!! y yo pensando que nunca me iba a fallar. Por su culpa, ahora tiene que parar la mente! Llega la quimio. Ja! ahora no puedes ni moverte ! tu cuerpo no se sostiene, y tu cabeza se termina de bloquear. Todo se ha parado!!.....hay silencio..... mi cuerpo es el centro. Le escucho en el silencio, le cuido en el dolor, le acaricio en el miedo.......es tan débil que es un cuerpo que se siente!!! ahora es parte de mi yo! Es otra de las cosas que aprendí del cáncer. Yo soy cuerpo. (blog 7)

Desde esta perspectiva, la experiencia del cáncer la conduce a la voluntad de "corporeizar" sus relaciones sociales, su deseo, su trabajo, su actividad política, refiriéndose a la voluntad de evidenciar la relevancia del cuerpo en estos espacios.

A pesar de esta tendencia a experimentar una mayor asociación con su cuerpo a raíz del cáncer en los blogs, en los blogs también aparece el cuerpo como algo disociado del sujeto, como algo que se tiene, que es ajeno:

Siento mi cuerpo como una especie de campo de batalla: unas fuerzas pugnan por conseguir una cosa y otras por todo lo contrario. Mientras, yo estoy en medio agotada (blog 4)

En la misma línea, aparece la enfermedad como un sujeto externo que ataca el cuerpo (Karas y Karner, 2005): la autora del blog 2 dedica varios posts al "Sr. Cáncer", al que también se refiere como "el enemigo" o "el puñetero inquilino", mientras que la autora del blog 5 en una ocasión se refiere al cáncer como "el demonio".

A nivel gráfico, el cuerpo disociado se manifiesta en las imágenes de posts que explican el tratamiento médico y sus efectos secundarios, mostrando un cuerpo que aparece fragmentado. De las 61 imágenes que muestran en detalle los efectos del tratamiento, en 44 el cuerpo aparece fragmentado, en planos cortos de las diferentes partes afectadas.

Como plantea Frank (1995), disociarse del cuerpo es una consecuencia de sentirlo como una amenaza a su vida. Por ejemplo, una autora del blog 7, ante la posibilidad de perder el pecho, explica: "a la teta herida la cuido como a un gato abandonado". Y así cuenta la autora del blog 5 la relación con su cuerpo mientras esperaba la mastectomía:

me di cuenta que hacía muchos días que inconscientemente evitaba ver mi cuerpo desnudo reflejado en el espejo. También reconocí que, sin darme cuenta, no me había palpado los pechos hacía muchos días. Ahora era consciente de una nueva relación con mi cuerpo y supe que odiaba cada centímetro de mi piel: en realidad aborrecía, detestaba y rechazaba especialmente la zona de mis mamas. (...) No los perdí [mis pechos] cuando me dijeron que tenía cáncer de mama. Los perdí en el preciso instante en que mi mente me dijo que si seguían conmigo me matarían. (5) (blog 5)

Una vez hecha la mastectomía bilateral e implantadas las nuevas prótesis, la autora afirma que continúa sintiéndose mutilada, que no percibe los pechos reconstruidos como propios ("los noto como si fueran dos pelotas pegadas a mi cuerpo") y que no puede mirar al es- 
pejo su cuerpo con los efectos de la quimioterapia ("No me reconozco"). Esta disociación empieza con el diagnóstico y se suaviza nueve meses después de la mastectomía:

por fin he sido capaz de palparme las mamas. (...) Hacía días que me daba vueltas por la cabeza la idea de empezar a entablar una relación con ellas, ya que tendremos que convivir hasta el resto de nuestras vidas. Pero sólo imaginarme la situación me creaba pánico, dolor en el estómago y ganas de llorar. Hasta que, un mediodía, sin darle tiempo a mi cerebro a pensar ni a reaccionar, en cuanto me vino la idea a la cabeza, me tumbé en el sofá. Puse cada una de mis temblorosas manos encima de cada uno de mis senos. (...) Ahora, mis mamas y yo hemos empezado a conocernos y a ser amigas. Seguro que nos llevaremos muy bien. Ya no les tengo miedo. (blog 5)

Como muestra la cita, a pesar de estar relatando cómo va haciendo pasos para aceptar su cambio corporal, continúa hablando de los pechos de forma disociada.

En contraste con esta experiencia, una autora del blog 7 explica cómo la mastectomía generó un cuerpo en el que se siente a gusto porque está acorde con su vivencia no normativa de la identidad de género: "Un cuerpo propio, que no solo no cuestiona mi masculinidad femenina, sino que la hace más confortable!....no es leíble, pero es un cuerpo propio".

\subsection{Control}

En los blogs aparece con frecuencia la voluntad de tener un cuerpo bajo control, no afectado por las contingencias propias de la enfermedad y su tratamiento. En los blogs 2 y 4 se concreta sobre todo en la voluntad de tener un cuerpo que pueda sostener el ritmo de trabajo anterior a la enfermedad. En ambos casos se trata de trabajos cualificados y que las hacen sentir realizadas. A la autora del blog 4, docente, le duele coger la baja y trata de convencer a los médicos para acortarla. Además, su insistencia para tener un cuerpo predictible se evidencia en que durante la quimioterapia, realiza viajes, actividades lúdicas, cursa un ciclo formativo y lleva a cabo una mudanza.

En el caso de la autora del blog 2, durante el período de la quimioterapia se empeña en continuar trabajando (en el mundo audiovisual), lo que implica trasladarse a otras ciudades, madrugar y largas jornadas de grabación. Afirma que "mi trabajo me da la vida" y se refiere a los períodos en que trabaja como "vacaciones" de la convalecencia: "quiero darme a mí misma la sensación de que todo va a volver a ser como siempre y eso me hace sentir iiviva!!".

Mediante las metáforas bélicas (Sontag, 1990) la autora del blog 2 plantea su proceso como una "guerra" contra el cáncer para ganar el control del cuerpo: "Hace mucho que paraste mi vida, que tomaste sus riendas por un tiempo, pero yo me he vuelto a adueñar de lo que nunca me debiste quitar".

La voluntad de mantener el cuerpo bajo control se presenta también en los blogs a través del lenguaje de la supervivencia, que se traduce en llevar a cabo cambios en el 
estilo de vida para favorecer la curación. Está especialmente presente en los blogs 1 y 3 , cuyas autoras practican yoga, deporte, cuidan su alimentación, recurren a terapias alternativas y leen y recomiendan libros de autoayuda. Todas estas acciones las entienden como complementarias a la medicina convencional. A nivel gráfico, la autora del blog 1 es la que más refiere esta búsqueda de la predictibilidad, mostrando imágenes de libros sobre pensamiento positivo o "dieta anti-cáncer", de alimentos beneficiosos y de buenos hábitos.

Realizar cambios que estén al alcance de la paciente para favorecer su curación se puede interpretar como una reacción a la impotencia que les genera sentir que dependen exclusivamente de la actuación médica. Así, la autora del blog 1 relata que pasó de la "etapa de la resignación", en la que relegaba su curación a los médicos, a convertirse en agente de su proceso: "hay muchas cosas que podemos hacer para luchar contra el cáncer”. En la misma línea, es especialmente ilustrativo cuando la autora del blog 3 relata el momento en que decide dejar de buscar información sobre su enfermedad:

no quiero, ni estoy preparada para leer cosas de las que yo no controlo, las cuales no tengo ni idea como interpretar y que seguramente acabe interpretando... pero a lo malo y mal. Así que, por primera vez en mi vida de paciente de cáncer he decidido... SER UN POCO IGNORANTE DE LO MIO!!!!.... esto como primera medida.... la segunda ya es dejar de fumar y la tercera es mover el trasero por el paseo marítimo a bajar esos $3 \mathrm{Kg}$ que gané. (blog 3)

Así, ante la impotencia de no poder entender en profundidad la información médica, decide incidir en los cambios que tiene a su alcance: hábitos y estilo de vida.

En este marco aparece con fuerza la lógica según la cual las personas deben promover los pensamientos positivos y evitar los negativos para favorecer su curación (Held, 2002; Sumalla et al., 2013). Esta ideología, especialmente presente en los blogs 1, 2, 3 y 5 , plantea que la voluntad de la paciente es clave en el proceso de curación. Así lo expresa la autora del blog 5 a raíz de conocer a una mujer afectada de cáncer:

me pareció una mujer muy luchadora. Me gustó cuando dijo: "al diagnosticarme la enfermedad, tenía claro que no podía morirme... es que tengo dos hijas y no las podía dejar solas." Su expresión y mirada reflejaban una gran ilusión por vivir. Y lo conseguirá. Pienso que no hay nada más importante en la lucha contra el cáncer que tener pensamientos positivos, fuerza y esperanza. (blog 5)

Reproduciendo esta misma lógica, en el blog 3 encontramos afirmaciones como: "me voy a curar! (...) porque ahora tengo fe en mí"; "somos en un cien por cien responsables de todas nuestras experiencias"; y "Repítete diez veces cada hora 'Estoy sana' y olvídate de que tienes cáncer". Al sobredimensionar la capacidad individual para controlar el propio cuerpo, este discurso constituye un falso empoderamiento: tras la 
apariencia de dar margen al individuo, lo hace responsable hasta límites que no están a su alcance (Held, 2002; Pitts, 2004; Coll-Planas, 2014).

El pensamiento positivo implica varias consecuencias negativas más. En primer lugar, dificulta aceptar la vertiente negativa de la enfermedad y su tratamiento (también en Thomas-MacLean, 2004). Esto se traduce en la voluntad de esconder los efectos de la quimioterapia (con el uso de pelucas, de maquillaje, etc.), en tratar de esconder las cicatrices, y en no hablar de la muerte o hacerlo con evasivas (Lorde, 1980; Pitts, 2004). Por ejemplo, a nivel gráfico en ninguna ocasión las autoras muestran su alopecia en espacios públicos. Así, esta lógica dificulta aceptar la contingencia del cuerpo, más presente a raíz de la enfermedad. La autora del blog 1 , cuando le informan que tiene una menopausia prematura, afirma: “Cómo se digiere una noticia así? Pues directamente no se digiere, la ignoras, porque tengo 32 años y me niego a vivir una madurez física que no me corresponde".

En segundo lugar, otra consecuencia negativa del pensamiento positivo es que solamente se promueven las historias de superación, negando el espacio a la expresión de la desesperación, el dolor o el miedo a la muerte. Esto ejemplifica la resistencia cultural a escuchar la vertiente negativa de la enfermedad (Frank, 1995; Smith y Sparkes, 2007; Thomas-MacLean, 2004), algo común en la forma hegemónica de construir el cáncer de mama, que se basa en "celebrar la supervivencia ocultando la mortalidad y promoviendo la obediencia a los protocolos médicos" (Ehrenreich, 2001: 52).

En tercer lugar, esta lógica entraña la culpabilización de la persona sin una trayectoria de éxito, ya que implícitamente es acusada de no haber sabido controlar su cuerpo y sus emociones (Sontag, 1990; Held, 2002; Pitts, 2004; Bell, 2010; Coll-Planas, 2014).

En definitiva, reproducir la lógica del pensamiento positivo dificulta asumir la contingencia del cuerpo y el poder limitado que tienen ellas sobre el curso de su enfermedad. La siguiente cita de la autora del blog 2, la que más reproduce el pensamiento positivo, ilustra el coste de mantener este tipo de lógica:

Siento deciros que soy humana. Mientras he estado en tratamiento sólo veía la meta por la que tenía que cruzar y era la razón por la que me mentalizaba de que cualquier esfuerzo era bueno y merecía la pena. Y yo me he empeñado en que encima tenía que sonreír, ser un buen ejemplo para las que venían detrás, no dar demasiado el coñazo a los que me cuidaban y encima hacer ver que todo eso no me agotaba y lo llevaba genial... (...) Y es que he hecho un esfuerzo extra en intentar disfrutar del paisaje oscuro que me habían pintado, intentando ponerle colorines a mi gusto con un ímpetu tan grande, que eso me ha llevado a una extenuación que no me esperaba, porque realmente me había creído que tenía poderes de superwoman (blog 2)

De esta forma, la autora expresa como la exigencia de control emocional y la dificultad para admitir los aspectos negativos del proceso y la contingencia del cuerpo le han implicado un desgaste de energía que ha acabado pasando factura. 
En esta línea, en el blog 7 encontramos una crítica al pensamiento positivo por, precisamente, su imposibilidad de integrar la vertiente de la vulnerabilidad, el sufrimiento y el reconocimiento de nuestro carácter mortal:

me venden que ser positiva es lo ideal. (...) Pero otro pensamiento positivo me ayudó a caminar! el que te hace estar presente, con tus miserias y las de los demás: miedos, angustias, encrucijadas, apegos,.....que una ha de comprender y aceptar! donde la idea no es tapar, sino ser más consciente de mi realidad, de mi mortalidad.... (blog 7)

Si hasta ahora hemos examinado cuando aparece el ideal de cuerpo predictible en los blogs, ahora nos centramos en la aceptación de la contingencia. Ésta se traduce, por ejemplo, en entender las cicatrices como rastro de lo vivido y aquello que no quieren y no pueden olvidar. Así, las reivindican como muestra de que "he luchado, he vencido y he sobrevivido" (blog 6), y como recordatorio: "prometo que siempre estaré orgullosa de mis cicatrices (esas que todavía no puedo mirar sin cierto recelo a pesar de todo) y que esas marcas en el cuerpo serán mi principal motivo para seguir sonriendo a la VIDA" (blog 2). Una autora del blog 7 afirma: "Me niego a silenciar mis cicatrices para ocultar que existe la muerte". Se siguen así los planteamientos de Audre Lorde (1980), que denunciaba el intento de borrar el rastro del cáncer en el cuerpo mediante la reconstrucción quirúrgica de los senos y tratando de borrar las cicatrices. En esta línea, varios blogs se hacen eco de los proyectos fotográficos Costuras a flor de piel y The Scar Project, que retratan mujeres mostrando sus pechos después de la extirpación del tumor, e incluso la autora del blog 1 participa como modelo. Así, se critica la invisibilización social de los efectos del cáncer de mama y su tratamiento en el cuerpo:

Esta enfermedad cada día se vuelve un poco más mediática, reclamo publicitario y edulcorada. Juntas nos ponemos el pañuelo rosa y nos vamos a correr al Retiro (ojo, yo la primera), vemos como famosas estupendas posan en photocalls prestando sus pechos a la causa. Pero ¿sería lo mismo si en lugar de ver a la famosa de turno con su pañuelito dándonos su apoyo y diciéndonos lo fuertes que somos, apareciera una mujer que de verdad hubiera padecido cáncer con mastectomía a enseñarnos que estas cicatrices no se van ni con photoshop? (...) creo que la gente prefiere ponernos el lacito rosa y empaquetarnos como a un peluche, antes de ver que el cáncer te deja huella. Una huella demasiado profunda como para difuminarla. (blog 1)

En relación a la representación del rastro de la intervención en el pecho, solo la autora del blog 7, a la que se le ha practicado una mastectomía, la muestra abiertamente en el blog, precisamente en el primer post, como si se tratase de una declaración de intenciones: mostrar la enfermedad sin los convencionalismos y el pudor que se manifiesta en la mayoría de medios. La autora del blog 5, a la que se le practica una mastectomía 
bilateral y después se somete a una reconstrucción de los pechos, no muestra este proceso de forma explícita pero sí que enseña las cicatrices y moratones de la mastectomía en el torso, en una imagen en la que aparece en sujetador. Y, más adelante, mostrará primeros planos del proceso paulatino de la reconstrucción, siempre con el pecho cubierto. En total, la mastectomía o las cicatrices aparecen en seis ocasiones en los blogs, y en una de ellas se trata de la difusión de imágenes de The Scar Project, que muestra de forma clara las secuelas del cáncer de mama en los cuerpos de las mujeres que han sobrevivido a esta enfermedad. Otras de las blogueras que no se han sometido a mastectomías pero que sí que han realizado sesiones de radioterapia o se les ha colocado un reservorio en esta zona, muestran en ocasiones el torso semidesnudo en las fotografías, pero no se expone de una forma clara ni en ningún momento se ve el pezón. La representación del pecho intervenido hay que situarla en un contexto cultural más amplio en el que esta parte del cuerpo de las mujeres se construye como espacio de choque de los significados de feminidad, maternidad, deseo del Otro y placer erógeno (Young, 1992; Millsted and Frith, 2003; Smith, 2009; Sánchez, 2012).

El reconocimiento de la contingencia también lo encontramos en la práctica generalizada de cortarse el pelo antes de que caiga ("que la alopecia no me venza a mí sino más bien vencer yo a la alopecia", blog 3) convirtiéndolo en algunos casos en un evento social; en la reivindicación del uso del pañuelo en vez de la peluca para visibilizar el cáncer en el espacio público y combatir el estigma; en asumir aspectos considerados negativos del proceso como el cansancio, la desesperación o el miedo a la muerte; y en aceptar que, al contrario de lo que plantea la narrativa de la restitución, no existe la posibilidad de volver al estado previo a la enfermedad: "mi vida anterior irremediablemente ya no existe" (blog 2); "No digo recuperar mi vida, porque hay cosas que no se pueden recuperar y que tampoco quiero recuperar, cosas que se han quedado en el camino, pero sí quiero reconquistar una nueva vida" (blog 1).

La mayoría de textos que hacen referencia al deterioro físico no están ilustrados. Estos elementos están silenciados gráficamente en los blogs 1, 3 y 4 . Este hecho puede deberse en parte a la poca predisposición a tomar fotografías en momentos de crisis y de duelo (Sanz, 2007). En algunas ocasiones las imágenes del tratamiento se muestran después de un tiempo, como en el blog 1 . Solo los blogs 2 y 5 , y parte del 6 y 7 muestran imágenes e ilustraciones del detalle del tratamiento y los efectos secundarios en el cuerpo.

La aceptación más radical de la contingencia del cuerpo es asumir su carácter finito, mortal, algo que la cultura dominante trata de negar (Bauman, 1992; Coll-Planas, 2012). De hecho, llama la atención lo poco que se habla directamente de la muerte aunque es un tema que planea a menudo detrás de los posts (Coll-Planas, 2014). En la mayoría de blogs, cuando se menciona se hace mediante evasivas ("esta lucha me puede costar la vida", "la fecha de caducidad de las personas", blog 2) y solo se representa indirectamente en dos ocasiones a través de las fotografías de mujeres que han fallecido debido a la enfermedad. 
En este sentido, el blog 7 vuelve a ser la excepción, pues es el único que aborda de una forma muy directa el tema de la mortalidad. De hecho, su autora más prolífica firma como Dra. Cadáver y considera que uno de los aspectos positivos del cáncer es que la ha hecho consciente de su carácter mortal:

Un diagnóstico de cáncer es un regalo. Nos recuerda ke vamos a morir. Si sobrevivimos, nos da el coraje para eliminar las idioteces de nuestras vidas, vivamos lo ke vivamos tras el cáncer, el diagnóstico nos ha obligado a plantearnos el no ser, el acabarse. Es una oportunidad maravillosa. Es una bendición. (blog 7)

En el mismo blog encontramos una fotografía en que se muestra a una de las autoras escenificando paródicamente su propia muerte.

\section{Conclusiones}

Como hemos visto, en los blogs analizados, el cuerpo se representa como deseante: con energía para comunicar, para crear, para generar proyectos. De hecho, el diagnóstico de cáncer y la confrontación con la idea de la mortalidad es un elemento que lleva a las autoras a querer vivir la vida más intensamente.

El cuerpo, además, se presenta de una forma principalmente diádica, aspecto atribuible al hecho de estar analizando blogs. Esto se observa por el peso que se da a la mirada del otro, por el hecho de reconocer su interdependencia y porque la enfermedad suele estimular el vínculo con otras personas que sufren. Tanto los proyectos que emprenden como los vínculos que generan a raíz de la enfermedad se viven de una forma individualista (a partir de cambios en el propio estilo de vida y en la relación con las personas del entorno) o colectiva (sentando la base para procesos que involucran más personas en una causa común).

Sobre la relación con el cuerpo encontramos los dos polos. Por un lado, aparece el cuerpo disociado: como algo que se tiene, que es ajeno y fragmentable. Así, el diagnóstico de la enfermedad se muestra como una noticia que puede desembocar precisamente en distanciarse del cuerpo, ya que es vivido como una amenaza a la propia vida. Por otro lado, encontramos la tendencia opuesta: que la enfermedad precisamente lleve a la conexión, a la escucha del cuerpo.

En relación al control, se produce una fuerte tensión entre la voluntad de predictabilidad y la aceptación de la contingencia. La predictibilidad se trata de conseguir a través de dos vías: el control de la imagen (el cuerpo especular del que habla Frank, 1995) o el control de sus procesos para favorecer la curación a través de cambios en el estilo de vida y en la gestión emocional (cuerpo disciplinado). La contingencia aparece en la aceptación de los rastros corporales de la enfermedad y el tratamiento, pero se percibe una clara dificultad para asumirla plenamente, lo que se traduce en la no asunción de la mortalidad. 
Esto plantea un panorama ambivalente respecto a las posibilidades que ofrecen los blogs para generar nuevos imaginarios sobre el cuerpo enfermo. Por un lado, hay elementos que siguen la lógica moderna de la vivencia de la enfermedad: se busca la predicatibilidad del cuerpo y su restitución, se tratan de esconder los efectos secundarios, no se asume la mortalidad, no hay un cuestionamiento a la lógica médica y, en varias ocasiones, aparece un cuerpo monádico y disociado. Por el otro, sin embargo, encontramos un cuerpo deseante, con proyectos que van más allá de seguir los consejos médicos, un cuerpo que se entiende como nódulo de una red de afectos, cuidados y solidaridad, y que se esfuerza por asumir y visibilizar el rastro corporal del proceso vivido.

\section{Bibliografía}

Bauman, Z. (1992): Mortality, Inmortality \& Other Life Strategies, Standford, Stanford University Press.

Bekerman, J. (1996): El psicoanálisis ilustrado, Buenos Aires, Emecé.

BeLL, K. (2010): "Cancer survivorship, mor(t)ality and lifestyle discourses on cancer prevention", Sociology of health \& illness, 32(3), pp. 349-364.

Cabruja, T., L. IÑiguez y F. VÁzquez (2000): “Cómo construimos el mundo: relativismo, espacios de relación y narratividad", Anàlisi, 25, pp. 62-94.

Coll-Planas, G. (2012): La carne y la metáfora. Una reflexión sobre el cuerpo en la teoría queer, Barcelona/Madrid, Egales.

Coll-Planas, G. (2014): “«Me quedaré con lo positivo»: Análisis de blogs de mujeres con cáncer de mama", Aloma, 32(1), pp. 33-44.

Coll-Planas, G., E. Alfama y M. Cruells (2013): "Se_nos gener@ mujeres. La construcción discursiva del pecho femenino en el ámbito médico", Athenea Digital, 13(3), pp. 121-135.

Elias, N. (1989): El proceso de la civilización. Investigaciones sociogenéticas y psicogenéticas, Madrid, Fondo de Cultura Económica.

Fisher, P. \& D. Goodley (2007): "The linear medical model of disability: mothers of disabled babies resist with counter-narratives", Sociology of health \& illness, 29(1), pp. 66-81.

Frank, A. (1995): The Wounded Storyteller. Body, Illness, and Ethics, Chicago, The University of Chicago Press.

Goffman, E. (1986): Estigma. La identidad deteriorada, Buenos Aires, Amorrortu.

Gooden, R.J. \& H.R. Winefield (2007): "Breast and Prostate Cancer Online Discussion Boards A Thematic Analysis of Gender Differences and Similarities", Journal of Health Psychology, 12 (1), pp. 103-114. 
Gualtieri, L. \& F.Y. Akhtar (2013): “Cancer Patient Blogs: How Patients, Clinicians, and Researchers Learn from Rich Narratives of Illness", en Actas del 35th International Conference on Information Technology Interfaces, Cavtat, University of Zagrev.

Held, B.S. (2002): "The Tyranny of the Positive Attitude in America: Observation and Speculation”, Journal of clinical psychology, 58(9), pp. 965-991.

HydÉn, L-C. (1997): "Illness and narrative”, Sociology of health \& illness, 19 (1), pp. 48-69.

IzQUiERdo, M.J. (1998): El malestar en la desigualdad, Madrid, Cátedra.

KARAS, J., \& T.X. KARNER (2005): “Understanding the diabetic body-self”, Qualitative health research, 15 (8), pp. 1086-1104.

Le Breton, D. (2002): Antropología del cuerpo y modernidad, Buenos Aires, Nueva visión.

Lorde, A. (1980): The Cancer Journals, San Francisco, Aunt Lute Books.

McCosker, A. (2008): "Blogging Illness: Recovering in Public", M/C Journal, 11 (6).

Martin, E. (2001): The Woman in the Body. A Cultural Analysis of Reproduction, Boston, Beacon Press.

Mathieson, C.M. \& S. Hendaikns (1995): "Renegotiating identity: cancer narratives", Sociology of health \& illness, 17 (3), pp. 283-306.

Millsted, R. \& H. Frith (2003): "Being large-breasted: Women negotiating embodiment”, Women's Studies International Forum, 26 (5), pp. 455-465.

Nosek, M., H. Powell Kennedy \& M. Gudmundsdottir (2012): “Chaos, restitution and quest: one woman's journey through menopause”, Sociology of health \& illness, 34 (7), pp. 994-1009.

Pierret, J. (2003): "The illness experience: state of knowledge and perspectives for research", Sociology of health \& illness, 25 (3), pp. 4-22.

PitTs, V. (2004): "Illness and Internet empowerment: writing and reading breast cancer in cyberspace", Health, 8 (1), pp. 33-59.

RESSLER, P.K. et al. (2012): “Communicating the Experience of Chronic Pain and Illness Through Blogging”, J Med Internet Res, 14 (5).

SANCHEZ TAYLOR, J. (2012): "Fake breasts and power: Gender, class and cosmetic surgery", Women's Studies International Forum, 35 (6), pp. 458-466.

SANZ, F. (2007): La fotobiografía, Barcelona, Kairós.

SEAlE, C. (2002): "Cancer heroics: a study of news reports with particular reference to gender”, Sociology, 36 (1), pp. 107-26.

SEALE, C. (2005): "New directions for critical internet health studies: representing cancer experience on the web", Sociology of health \& illness, 27 (4), pp. 515-540.

SHAPIRO, J. (2011): "Illness narratives: reliability, authenticity and the empathic witness", Medical humanities, 37 (2), pp. 68-72. 
Sмiтн, C.P. (2009): The politics of the marked body: an examination of female genital cutting and breast implantation, University of Oregon, Eugene.

Smith, B. \& A.C. Sparkes (2008): "Changing bodies, changing narratives and the consequences of tellability: A case study of becoming disabled through sport", Sociology of health \& illness, 30 (2), pp. 217-236.

SonTAG, S. (1990): Illness as metaphor, New York, Anchor Books.

Sumalla, E.C., C. Ochoa e I. Blanco (2013): “«Pero...¿estoy curada?». Narración de restitución y discurso biomédico en cáncer de mama”, en Àngel Martínez-Hernández, Lina Massana y Susan M. Digiacomo, eds., Evidencias y narrativas en la atención sanitaria Una perspectiva antropológica, Tarragona/Portoalegre, Publicacions de la URV y Rede Unida.

Thomas, C. (2010): "Negotiating the contested terrain of narrative methods in illness contexts", Sociology of health \& illness, 32 (4), pp. 647-660.

Thomas-MacLean, R. (2004): "Understanding breast cancer stories via Frank's narrative types", Social science \& medicine, 58 (9), pp. 1647-1657.

Turner, B.S. (1992): Regulating Bodies. Essays in Medical Sociology, London, Routledge.

VAlerio, M. (2013): "Fotografías con alma solidaria”, El Mundo, 25 de enero.

VISA, M. (2013): L'àlbum fotogràfic familiar. Un relat socialtzat de la pròpia vida, Lleida, Publicacions UDL y IEI.

Wentzer, H.S. \& A. Bygholm (2013): "Narratives of empowerment and compliance: Studies of communication in online patient support groups", International journal of medical informatics, 82 (12), pp. e386-e394.

Young, I.M. (1990): Throwing Like a Girl: And Other Essays in Feminist Philosophy and Social Theory, Bloomington, Indiana University Press. 